\title{
How can we use nanophotonics to help in combating climate change?
}

\author{
Hilmi Volkan Demir \\ Department of Physics and Department of Electrical and Electronics Engineering \\ Nanotechnology Research Center and Institute of Materials Science and Nanotechnology \\ Bilkent University, Ankara, Turkey \\ www.bilkent.edu.tr/ volkan \\ volkan@bilkent.edu.tr
}

Climate change is one of the major issues that we face in our century [1]. Today as a scientific fact, it is observed that the emission rate of greenhouse gasses including carbon dioxide and nitrous oxide is on an alarmingly rapid rise [2]. Looking forward to the era of nanotechnology, one natural question to pose is "can nanotechnology help in combating this major problem?" According to recent studies [3-5], the answer is yes, but it is a cautious one. Nanotechnology and other technologies need to work hand in hand. A variety of possible solutions that nanotechnology offers include examples in photovoltaic technology for solar cells, hydrogen economy and fuel cells, fuel additives to increase the efficiency of diesel engines, batteries and supercapacitors for energy storage, and improved insulation for buildings. As a matter of fact, nanoparticles are already in industrial use for this purpose. For example, molybdenum disulphide nanocrystals are used as catalysts to remove potentially harmful sulphur compounds from crude oil. [3]

In nanophotonics, as a subfield of nanotechnology, one of our tasks is to incorporate custom-design nanomaterial into photonic devices and systems for the realization of different optical functionalities favorably controlled with external effects. In my research group, to this end, we work on the development and demonstration of new hybrid nanophotonic devices and systems that consist of different combinations of nanomaterials and nanostructures put together in hybrid architectures (e.g., [6-18]). These devices and systems operate in a wide range of optical spectrum from the ultraviolet (UV) to the visible to the infrared (IR) and serve a variety of optical functions for a long range of applications including light generation, modulation, sensing, imaging, displays, communications, alternative energy generation, and environmental decontamination. Examples of these nanomaterials employed in our devices include epitaxially grown quantum structures; in-solution synthesized semiconductor nanocrystals, metal nanoparticles, and polymer nanoparticles; electroplated, evaporated, or patterned metal nanostructures, and grinded semiconductor nanoparticles [6-18].

In particular to help combat climate change, in our research group, we ask ourselves "How can we use nanophotonics?" This question can of course be tackled in many different approaches. Among the others, we investigate three specific questions to seek answers for "how": 1.) Can we generate high quality white light in solid state lighting based on LED platforms to reduce the global energy consumption? 2.) Can we produce more efficient solar cells based on Si for alternative energy generation? 3.) Can we offer means to reduce the amount of emitted $\mathrm{CO}_{\mathrm{x}}, \mathrm{NO}_{\mathrm{x}}$ and other greenhouse gases?

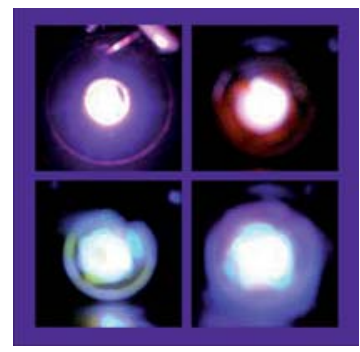

Fig. 1. Nanocrystal emitters hybridized on LEDs to generate and tune white light [6].

For the first question, we are working on nanocrystal hybridized white LEDs (Fig. 1 [6]) for the generation of high-quality, tunable white light [6-15]. Currently, about $20 \%$ of global energy production is consumed for lighting; LED based solid state lighting potentially offers $50 \%$ reduction in the energy consumption, corresponding to a significant carbon emission reduction (as large as 300 million tons annually). Currently available commercial LEDs, however, typically provide cool white light with a low color rendering index $(\sim 70)$. Using multiple combinations of nanocrystals, we achieved warm white light with high color 
rendering index $(\sim 80)$ meeting the requirements of future lighting [7]. Also, we successfully demonstrated white light generation and tuning using polymer-nanocrystal assemblies [8,9], white emitting nanocrystal luminophores [10], and multiple color emitting heteronanocrystals $[11,12]$, both using blue $[6,7]$ and $n$ UV LED platforms $[13,15]$. We also utilized metal nanostructures to control and enhance spontaneous emission from nanocrystal emitters [14].

For the second question, to produce alternative efficient energy sources, we developed photovoltaic nanocrystal scintillators hybridized on Si solar cells to extend solar conversion toward UV [16, 17]. Our nanocrystal hybridized scintillators led to significant enhancement in optical responsivity in UV (experimentally by two orders of magnitude enhancement) [16], and two fold enhancement in the solar conversion efficiency under white light illumination [17].

Finally, for the third generation, to help reducing greenhouse gas levels, we are working on photocatalytic nanocomposite systems for massive environmental decontamination (in collaboration with our industrial partner DYO) [18]. We demonstrated time evolution of optical spectral efficiency curves and strong size effect in our UV and visible photocatalytic organic-inorganic nanocomposites.

In conclusion, as emerging technologies enabled by nanophotonics to combat climate change, we developed and demonstrated 1.) nanocrystal hybridized white light sources and those also embedded with plasmonic metal nanoparticles for the reduction of global energy consumption, 2.) photovoltaic nanocrystal scintillators hybridized on solar cells for the generation of efficient green energy sources, and 3.) photocatalytic nanoparticle and nanocomposite systems for massive environmental decontamination, all to contribute to the reduction of greenhouse gas amount.

References:

1. IPCC Climate Change 2007, "Is the Current Climate Change Unusual Compared to Earlier Changes in Earth's History?," FAQ chapter, p. 114 (2007).

2. IPCC Climate Change 2007, Human and Natural Drivers of Climate Change, Summary for Policymakers, p. 2 (2007).

3. Nature Nanotechnology, "Combating Climate Change", editorial, 2(6), p. 325 (2007).

4. Oakdene Hollins, "Enviromentally Beneficial Nanotechnologies, Barriers and Opportunities; a report for the Department of Environment, Food, and Rural Affairs," UK, May 2007.

5. Karen F. Schmidt, "Green Nanotechnologies," Woodrow Wilson International Center for Scholars, USA, April 2007.

6. S. Nizamoglu, T. Ozel, E. Sari, and H. V. Demir, Nanotechnology, 18(6), 065709 (2007).

7. S. Nizamoglu, G. Zengin, and H. V. Demir, Applied Physics Letters, 92, 031102 (2008).

8. H. V. Demir, S. Nizamoglu, T. Ozel, E. Mutlugun, I. O. Huyal, E. Sari, E. Holder, and N. Tian, New Journal of Physics, 9, 362 (2007).

9. I. O. Huyal, T. Ozel, U. Koldemir, S. Nizamoglu, D. Tuncel, and H. V. Demir, Optics Express, 16(2), 1115-1124 (2008).

10. S. Nizamoglu, E. Mutlugun, T. Özel, H. V. Demir, S. Sapra, N. Gaponik, A. Eychmüller, Applied Physics Letters 92, 113110 (2008).

11. S. Nizamoglu and H. V. Demir, Optics Express 16(6),3515-3526 (2008).

12. S. Nizamoglu, E. Mutlugun, O. Akyuz, N. Kosku Perkgoz, H. V. Demir, L. Liebscher, S. Sapra, N. Gaponik, A. Eychmüller, New Journal of Physics 10, 023026 (2008).

13. S. Nizamoglu and H. V. Demir, Nanotechnology, 18(40), 405702 (2007).

14. I. M. Soganci, S. Nizamoglu, E. Mutlugun, O. Akin, and H. V. Demir, Optics Express, 15(22), 1428914298 (2007).

15. S. Nizamoglu and H. V. Demir, J. Opt. A: Pure Appl. Opt., Special Issue on Nanophotonics, 9(9), S419-S424 (2007).

16. E. Mutlugun, I. M Soganci, and H. V. Demir, Optics Express 16(6), 3537-3545 (2008).

17. E. Mutlugun, I. M. Soganci, and H. V. Demir, Optics Express, 15(3), 1128-1134 (2007).

18. S. Tek, E. Mutlugun, I. M. Soganci, N. Kosku Perkgoz, D. Yucel, G. Celiker, and H. V. Demir, Journal of Nano Photonics, 1, 011685 (2007). 